\title{
Evidence for a Close Phylogenetic Relationship between Melissococcus pluton, the Causative Agent of European Foulbrood Disease, and the Genus Enterococcus
}

\author{
J. CAI AND M. D. COLLINS* \\ Department of Microbiology, Institute of Food Research, Reading Laboratory, Reading RG6 2EF, United Kingdom

\begin{abstract}
The 16S rRNA gene sequence of Melissococcus pluton, the causative agent of European foulbrood disease, was determined in order to investigate the phylogenetic relationships between this organism and other low-G $+C$ content gram-positive bacteria. A comparative sequence analysis revealed that $M$. pluton is a close phylogenetic relative of the genus Enterococcus.
\end{abstract}

\begin{abstract}
"Bacillus pluton," the primary etiological agent of European foulbrood of the honey bee, Apis mellifera, was originally described by White (14). This bacterium was first cultured and characterized in detail by Bailey (1) and was reclassified as "Streptococcus pluton" by him. The taxonomic position of " $S$. pluton" has always been problematic, and the species was not included on the Approved Lists of Bacterial Names (12). Bailey and Collins (3) assigned " $S$. pluton" to a new genus, Melissococcus, on the basis of the results of phenotypic studies (2). Our knowledge concerning the genetic interrelationships of streptococci and related low-G $+\mathrm{C}$-content gram-positive taxa has improved considerably in recent years with the application of nucleic acid hybridization and $16 \mathrm{~S}$ rRNA sequencing techniques. As a result, the genus Streptococcus is now primarily restricted to pyogenic and oral species (10). The "lactic" (or Lancefield group N) and "fecal" (Lancefield group D) streptococci have been assigned to two new genera, Lactococcus and Enterococcus, respectively (9-11). More recent comparative 16S rRNA sequencing data have shown that the genus Lactococcus is phylogenetically more closely related to the genus Streptococcus than to the genus Enterococcus (4). The latter genus is phylogenetically closely related to the genera Carnobacterium and Vagococcus $(4,13,15)$. Until now, there has been no information concerning the phylogenetic affinities of the genus Melissococcus. In this paper we describe the 16S rRNA gene sequence of Melissococcus pluton and the results of a comparative analysis performed with other catalase-negative, low-G+C-content, gram-positive bacteria.

$M$. pluton NCDO $2443^{\mathrm{T}}$ ( $\mathrm{T}=$ type strain) was grown as described by Bailey and Collins (2), and chromosomal DNA was prepared by using the method of Farrow et al. (6). The 16S rRNA gene of $M$. pluton NCDO $2443^{\mathrm{T}}$ was amplified by a PCR and was sequenced directly by using a Sequenase version 2.0 sequencing kit (U.S. Biochemicals) as described previously (8). Sequences were aligned and similarity values were determined by using the Wisconsin Molecular Biology package (5). Phylogenetic trees were constructed by using neighbor-joining and unweighted pair group with mathematical average methods.

The $16 \mathrm{~S}$ rRNA gene sequence of $M$. pluton NCDO $2443^{\mathrm{T}}$ which we determined has been deposited in the GenBank data base under accession number X75751. This sequence consisted of 1,396 nucleotides, representing approximately $93 \%$ of the
\end{abstract}

\footnotetext{
* Corresponding author. Mailing address: AFRC Institute of Food Research, Reading Laboratory, Earley Gate, Whiteknights Road, Reading RG6 2EF, United Kingdom. Phone: 0734 357000. Fax: 0734 267917.
}

total $16 \mathrm{~S}$ rRNA primary structure. The derived $16 \mathrm{~S}$ rRNA sequence of $M$. pluton was aligned with more than 150 other low-G+C-content gram-positive $16 \mathrm{~S}$ rRNA sequences retrieved from the EMBL and GenBank data bases. For the initial homology analysis approximately 90 nucleotides proximal to the $5^{\prime}$ end of the molecule were removed because of problems in aligning the hypervariable V1 region, which is different lengths in phylogenetically diverse taxa. After we established the closest relatives of $M$. pluton, however, this stretch of sequence could be aligned unambiguously and was

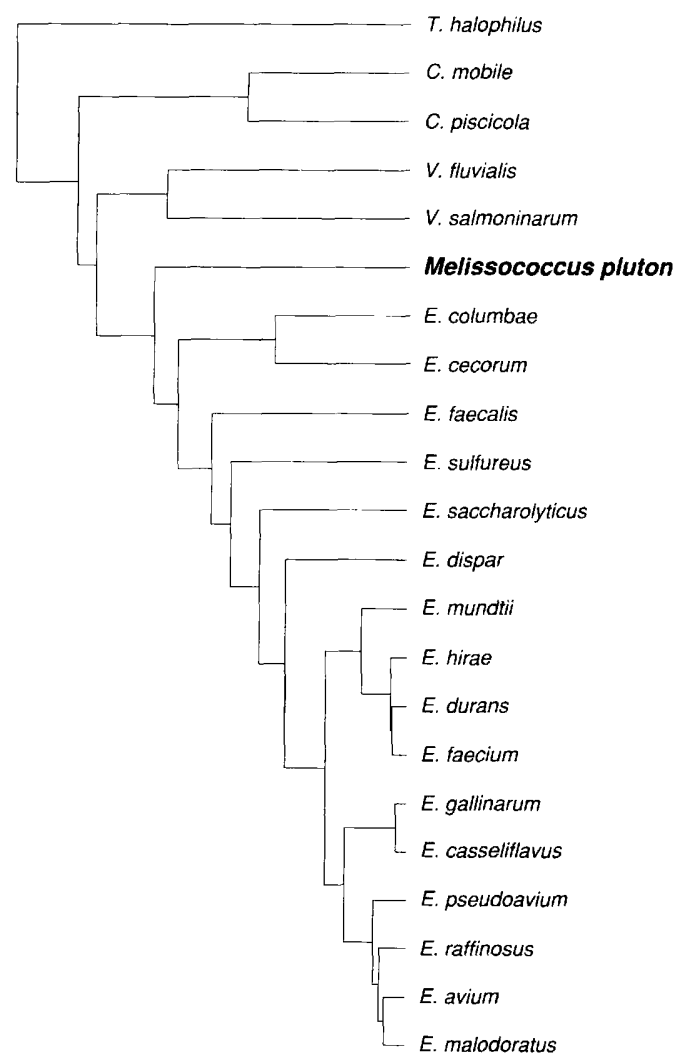

FIG. 1. Dendrogram showing the relationships of $M$. pluton, enterococci, and other low-G+C-content gram-positive organisms. Clustering was by the unweighted pair group method. T., Tetragenococcus; C., Carnobacterium; V., Vagococcus; E., Enterococcus. 
TABLE 1. Levels of sequence similarity for a 1,396-nucleotide region of the $16 \mathrm{~S}$ rRNAs of $M$. pluton and closely related low-G+C-content gram-positive organisms

\begin{tabular}{|c|c|c|c|c|c|c|c|c|c|c|c|c|c|c|c|c|c|c|c|c|c|}
\hline \multirow[b]{2}{*}{ Strain } & \multicolumn{21}{|c|}{$\%$ Sequence similarity to: } \\
\hline & 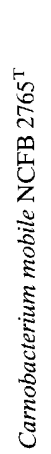 & 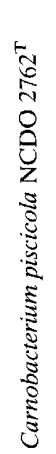 & 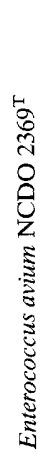 & 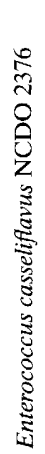 & 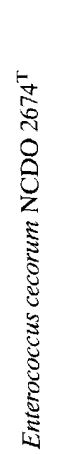 & 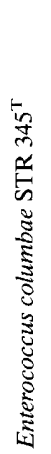 & 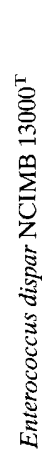 & 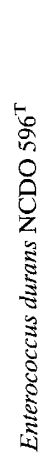 & 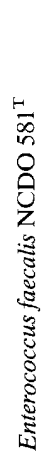 & 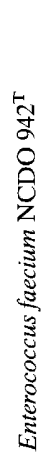 & 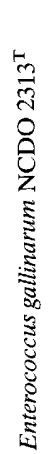 & 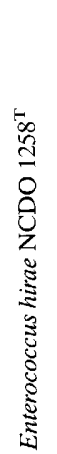 & 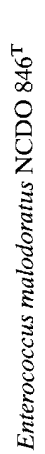 & 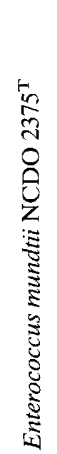 & 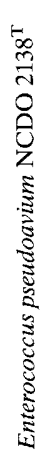 & 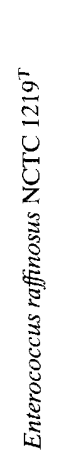 & 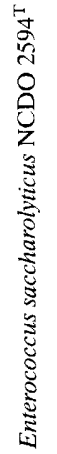 & 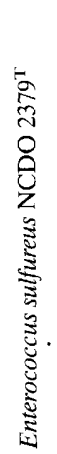 & 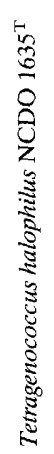 & 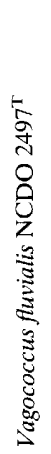 & 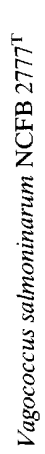 \\
\hline
\end{tabular}

Melissococcus pluton NCDO $2443^{\mathrm{T}}$

Carnobacterium mobile NCFB $2765^{\mathrm{T}}$

Carnobacterium piscicola NCDO $2762^{\mathrm{T}}$

Enterococcus avium NCDO $2369^{\mathrm{T}}$

Enterococcus casseliflavus NCDO 2376

Enterococcus cecorum NCDO $2674^{\mathrm{T}}$

Enterococcus columbae STR $345^{\mathrm{T}}$

Enterococcus dispar NCIMB $13000^{\mathrm{T}}$

Enterococcus durans NCDO $596^{\mathrm{T}}$

Enterococcus faecalis NCDO $581^{\mathrm{T}}$

Enterococcus faecium NCDO $942^{\mathrm{T}}$

Enterococcus gallinarum NCDO $2313^{T}$

Enterococcus hirae NCDO $1258^{\mathrm{T}}$

Enterococcus malodoratus NCDO $846^{\mathrm{T}}$

Enterococcus mundtii NCDO $2375^{\mathrm{T}}$

Enterococcus pseudoavium NCDO $2138^{\mathrm{T}}$

Enterococcus raffinosus NCTC $1219^{\mathrm{T}}$

Enterococcus saccharolyticus NCDO $2594^{\mathrm{T}}$

Enterococcus sulfureus NCDO $2379^{\mathrm{T}}$

Tetragenococcus halophilus NCDO $1635^{\mathrm{T}}$

Vagococcus fluvialis NCDO $2497^{\mathrm{T}}$

Vagococcus salmoninarum NCFB $2777^{\mathrm{T}}$

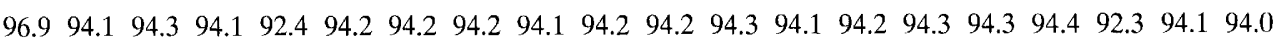

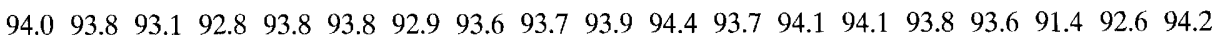

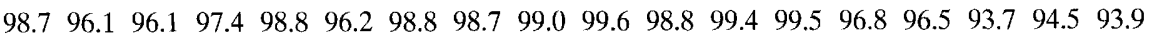

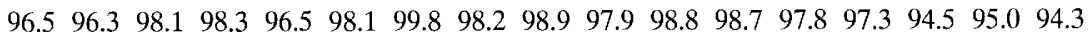

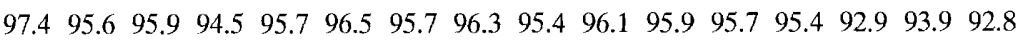

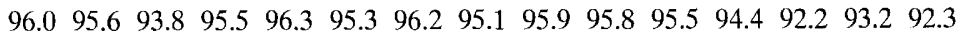

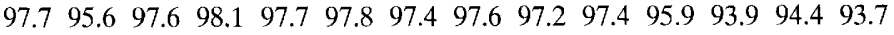

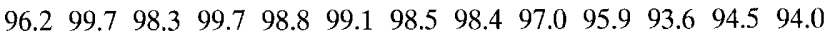

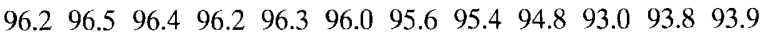
$\begin{array}{lllllllllll}98.2 & 99.7 & 98.8 & 99.0 & 98.5 & 98.5 & 97.1 & 96.0 & 93.3 & 94.0 & 93.9\end{array}$

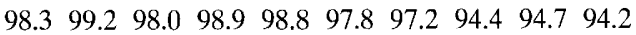

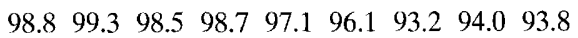
$98.599 .599 .5 \quad 97.3 \quad 96.793 .594 .694 .1$ 98.398 .396 .696 .293 .794 .394 .1 99.296 .796 .593 .694 .793 .8

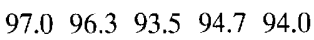
96.994 .293 .893 .8 93.794 .093 .7 91.091 .5 therefore reintroduced to calculate percentages of similarity. Representative sequence similarity values for $M$. pluton and its closest relatives are shown in Table 1 , and a phylogenetic tree is shown in Fig. 1.

The 16S rRNA sequence of $M$. pluton exhibited very low levels of similarity with the sequences of streptococci (approx- imately 87 to $89 \%$ ), and thus $M$. pluton is phylogenetically only remotely related to the genus Streptococcus (data not shown). $M$. pluton exhibited the highest levels of sequence similarity with enterococci (range, approximately 94 to $96 \%$ ), carnobacteria $(92 \%)$, and vagococci $(93 \%)$ (Table 1). The results of the treeing programs were consistent with the findings described 
above, and $M$. pluton clustered at the periphery of the genus Enterococcus (15). Close, albeit more distant, relationships to the genera Carnobacterium, Vagococcus, and Tetragenococcus (formerly Pediococcus halophilus) were also observed (Fig. 1).

We found that on the basis of $16 \mathrm{~S}$ rRNA sequence data $M$. pluton is phylogenetically only remotely related to streptococci. Both evolutionary distance calculations and treeing programs revealed that $M$. pluton and enterococci are closely related. Additional evidence for a close affinity between these taxa comes from the report that Lancefield group D antigen occurs in $M$. pluton (7). Because of the close relationship between $M$. pluton and enterococci, it could be argued that these organisms should be placed in a single genus. However, we consider such a change in nomenclature to be unwise, as the monospecific genus Melissococcus (Bailey and Collins 1983) has nomenclatural priority over the genus Enterococcus (Schleifer and Kilpper-Bälz 1984). The genus Enterococcus currently contains 18 species, and this genus name is widely used and accepted by the scientific community. A change of name would in our opinion serve no useful purpose and would create unnecessary nomenclatural confusion. Hence, we believe that the fastidious cultural requirements and low $\mathrm{DNA} \mathrm{G}+\mathrm{C}$ content of $M$. pluton (2), together with the branch point of $M$. pluton at the periphery of the Enterococcus cluster (Fig. 1), are sufficient to justify retention of Melissococcus as a separate genus.

We are grateful to the Ministry of Agriculture, Fisheries and Food for supporting this work.

\section{REFERENCES}

1. Bailey, L. 1957. The isolation and cultural characteristics of Streptococcus pluton and further observations on 'Bacterium eurydice.' J. Gen. Microbiol. 17:39-48.

2. Bailey, L., and M. D. Collins. 1982. Taxonomic studies on Streptococcus pluton. J. Appl. Bacteriol. 53:209-214.

3. Bailey, L., and M. D. Collins. 1982. Reclassification of 'Streptococcus pluton' (White) in a new genus Melissococcus, and Melissococcus pluton nom. rev., comb. nov. J. Appl. Bacteriol. 53:215-217.

4. Collins, M. D., C. Ash, J. A. E. Farrow, S. Wallbanks, and A. M.
Williams. $1989.16 \mathrm{~S}$ ribosomal ribonucleic acid sequence analysis of lactococci and related taxa. Description of Vagococcus fluvialis gen. nov., sp. nov. J. Appl. Bacteriol. 67:453-460.

5. Devereux, J., P. Haeberli, and O. Smithies. 1984. A comprehensive set of sequence analysis programs for the VAX. Nucleic Acids Res. 12:387-395.

6. Farrow, J. A. E., D. Jones, B. A. Phillips, and M. D. Collins. 1983 Taxonomic studies on some group D streptococci. J. Gen. Microbiol. 129:1423-1432.

7. Glinski, Z. 1972. Investigations on the properties and antigenic structure of Streptococcus pluton. IV. Antigenic structure of Str. pluton. Med. Weter. 28:603-611.

8. Hutson, R. A., D. E. Thompson, and M. D. Collins. 1993. Genetic interrelationships of saccharolytic Clostridium botulinum types B, $\mathrm{E}$ and $\mathrm{F}$ and related clostridia as revealed by small-subunit rRNA gene sequences. FEMS Microbiol. Lett. 108:103-110.

9. Schleifer, K. H., and R. Kilpper-Bälz. 1984. Transfer of Streptococcus faecalis and Streptococcus faecium to the genus Enterococcus nom. rev. as Enterococcus faecalis comb. nov. and Enterococcus faecium comb. nov. Int. J. Syst. Bacteriol. 34:31-34.

10. Schleifer, K. H., and R. Kilpper-Bälz. 1987. Molecular and chemotaxonomic approaches to the streptococci, enterococci and lactococci: a review. Syst. Appl. Microbiol. 10:1-19.

11. Schleifer, K. H., J. Kraus, G. Dvorak, R. Kilpper-Bälz, M. D. Collins, and W. Fischer. 1985. Transfer of Streptococcus lactis and related streptococci to the genus Lactococcus: a review. Syst. Appl. Microbiol. 10:1-19.

12. Skerman, V. B. D., V. McGowan, and P. H. A. Sneath (ed.). 1980 Approved lists of bacterial names. Int. J. Syst. Bacteriol. 30:225420 .

13. Wallbanks, S., A. J. Martinez-Murcia, J. L. Fryer, B. A. Phillips, and M. D. Collins. 1990. 16S rRNA sequence determination for members of the genus Carnobacterium and related lactic acid bacteria and description of Vagococcus salmoninarum sp. nov. Int. J. Syst. Bacteriol. 40:224-230.

14. White, G. F. 1912. The cause of European foulbrood. U.S. Dep. Agric. Circ. 157:1-15.

15. Williams, A. M., U. M. Rodrigues, and M. D. Collins. 1991. Intrageneric relationships of enterococci as determined by reverse transcriptase sequencing of small-subunit rRNA. Res. Microbiol. 142:67-74. 